\title{
Forging a Match.com Relationship with Patients
}

\author{
Stephen Klasko, MD, MBA \\ Editor-in-Chief, \\ Healthcare Transformation; \\ President and CEO, \\ Thomas Jefferson University \\ and Jefferson Health
}

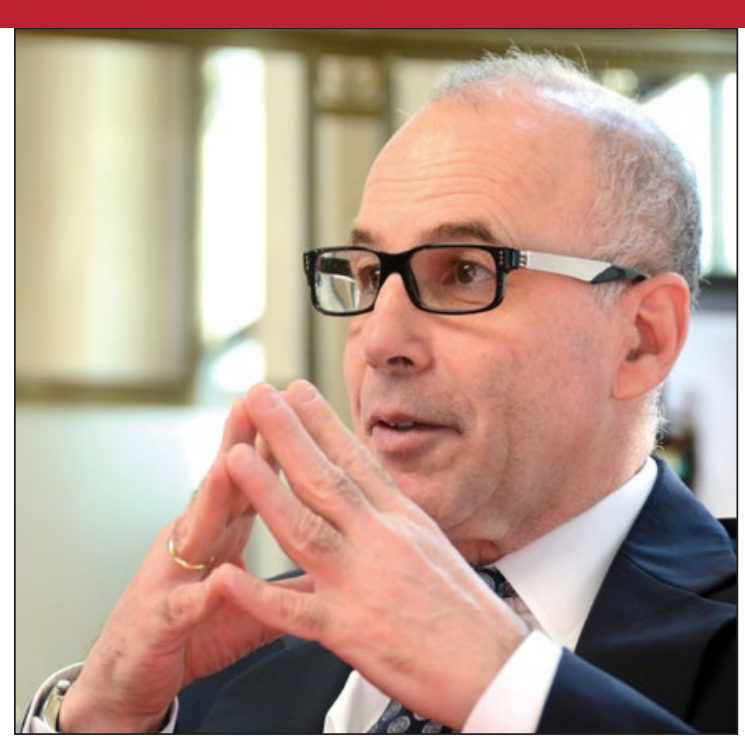

'm not a millennial, but there is hardly a thing I do where I don't consult

technology before making a decision.

Case in point: I met my wife on МАтсн.сом. That way, I could make an

intelligent decision after reading her detailed, extremely accurate profile. She

could likewise read my profile (some of which was true) and (fortunately) decide

to ping me. For those in the millennial generation and younger, a random meeting

in a bar or a blind-date scenario seems antithetical to their technology-first

approach.

All of which brings us to ... healthcare. It's not hard to predict that the least-

talked-about aspect of the disruption caused by younger generations will involve transparency and technology.

\section{- What Millennials Want}

Millennials won't tolerate a healthcare system untouched by the consumer revolution that has impacted every other aspect of their lives. At a time when they can do all their holiday shopping online while streaming Game of Thrones, the concept of waiting on the phone to listen to 11 options to get an appointment at a medical office, where they might wait an hour to see a caregiver, seems as retro as staying home so they won't miss their favorite TV shows.

It's no surprise that these expectations are changing the choices millennials make in healthcare. In a recent survey of patients under $\mathbf{4 0}$ done by JefFerson Health, we found that:

- $92 \%$ expect to have full two-way electronic communication with their providers;

- $\mathbf{8 3} \%$ expect to be able to access all their patient information online, as they do their bank accounts; 
- 78\% expect to have total access to family members' inpatient charts and be able to participate in rounds virtually;

- $\mathbf{7 1 \%}$ expect providers to have online scheduling and offer them the ability to compare rates by 2018 ; and

- $\mathbf{6 5 \%}$ expect to discuss health-related topics and compare providers via social media.

Clearly, many of us in healthcare have a lot of work to do to meet the expectations of the millennial patients already in our waiting rooms.

\section{- Meeting Millennial Expectations}

At Jefferson Health, we have taken the position that healthcare will, like everything else, be digital. So, we are going all in as we watch a once-in-a-lifetime event as healthcare goes from a business-to-business model to a business-to-consumer model and as we move from hospital companies to consumer health entities.

To that end, we have recruited and organized a team of millennials, led by an SVP and a chief digital officer, that reports directly to me. This Digital Innovation and Consumer Experience (DICE) group acts as a startup company within a two-century-old academic medical center. The DICE group comprises designers, creative application developers, and learning and solution analysts who design, develop, deliver, and support consumer-focused, value-driven digital solutions in concert with JEFFERSON staff, students, patients, and partners.

All of this is in response to a new reality. Many people under 40 have almost never had to go to a bank; they assume they can do their banking at home or on the run. Just as consumers don't talk about telebanking anymore, the millennial generation is not focused on whether you have a telehealth program; they simply expect total convenience and transparency in their interactions with your organization.

Healthcare needs to move quickly to meet these patient demands, as more and more patients expect to consume their healthcare in the flexible manner in which they deal with everything else in their lives.

As healthcare organizations, we need to define ourselves based on our care and caring rather than our location; we need to develop new definitions of patient satisfaction; and we need to pivot to being customer focused, as more of the dollars in healthcare consumption come from the patients themselves. All of that creates a buyer's market where convenience will be a differentiator. 


\section{- Finding Physicians the Match.com Way}

For us as physicians, perhaps the biggest change will be the need for transparency. Today, a person under 40 would never consider choosing a hotel without checking on Trip Advisor or YeLP. It is naïve for us to think that millennials will choose their doctors or hospital without that same level of transparency.

As an obstetrician, when a patient became pregnant, it used to be that her family doctor would "send her" to me. Most of the time, the patients took those referrals at face value, assuming that I must be the best.

Now, younger patients are demanding the equivalent of Матсн.сом to find obstetricians or midwives-and technology companies are offering apps to do this. Gone are the baby boomer days when patients would simply accept a doctor referral. Instead, they expect to be able to present their profile, express their needs, and have the opportunity to "match" with the best provider.

It is indeed a new world, and those health systems and doctors that view transparency and consumer technologies as futuristic roads too far will start to feel the pain. In 2003, I allowed technology to help me find a life match and start an optimistic personal future. In 2017, as the CEO of a U.S. News \& World Report Top 20 health system, I am counting on technology and consumerism to differentiate JEFFERSON and lead us to an optimistic financial and strategic future. AII 